\title{
Evaluation of an individualized education program in pituitary diseases: a pilot study
}

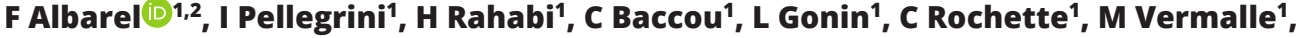 \\ T Cuny 1,2, F Castinetti (1,2 and T Brue ${ }^{1,2}$
}

${ }^{1}$ Department of Endocrinology, Assistance Publique-Hôpitaux de Marseille (AP-HM), Hôpital de la Conception, Centre de Référence des Maladies Rares de I'hypophyse HYPO, 13005 Marseille, France and ²Aix-Marseille Université, Institut National de la Santé et de la Recherche Médicale (INSERM) U1251, Marseille Medical Genetics (MMG), Institut Marseille Maladies Rares (MarMaRa), Marseille, France

Correspondence should be addressed to T Brue

Email

thierry.brue@univ-amu.fr

\begin{abstract}
Introduction: The low prevalence of pituitary diseases makes patient autonomy crucial, and self-management programs should be more common.

Objectives: To assess the efficacy of an education program for patients with pituitary diseases in terms of patients' quality of life, satisfaction and goal attainment.

Design and methods: Adult patients with pituitary disorders were recruited in a tertiary referral center and chose at least three of eight possible sessions on various topics, from disease management to psychosocial issues. Patients were included if they attended at least three sessions between 2012 and 2016 and completed the initial, final, and follow-up questionnaires. Data on quality of life (SF36), satisfaction and goal attainment were analyzed.

Results: Fifty-three patients were included (33 women; mean age, 53.5 years). There were a significant quality of life improvements in terms of physical and psychic limitation scores at the final assessment that persisted at follow-up evaluation. Most patients reached their objectives, especially those on sharing experiences and improving autonomy and self-confidence. More than half set new objectives at the end of the program, the most popular one being to reinforce their knowledge of their pituitary disease, its evolution and treatment (17.1\% of patients). The mean overall satisfaction score was 3.75/4. At follow-up evaluation, patients reported improved self-management of pituitary disease (3.6/5) and improved self-efficacy (3.8/5).

Conclusion: Individualizing the educational objectives of patients with pituitary disease improves the way they live with their disease. If confirmed in other cohorts, this approach could become the gold standard for education programs in rare endocrine diseases.
\end{abstract}

\section{Introduction}

Educating patients with rare diseases is crucial as this rarity makes management by non-specialized health professionals difficult. The degree of emergency of certain situations may be underestimated and their management suboptimal, which can, in some cases, put the patient's life at risk (1). It is, therefore, important for patients to acquire knowledge on their disease and its treatments, and to be
European Journal of Endocrinology

(2020) 183, 551-559 able to manage their medical condition autonomously, both in daily life and in emergency situations.

Education programs have been developed for many frequent chronic diseases (such as diabetes, asthma, hypertension, dyslipidemia, obesity) and in oncology, and most have been shown to improve patient outcomes (2). One noteworthy fact is that these programs are only 
seldom described in detail, which makes it difficult to form a clear idea of the characteristics of the educational modules that are the most effective. Education programs can be delivered in a wide variety of forms: in single or multiple sessions, with or without handouts - with spoken explanations or not - to be read or learnt, individually or in group sessions, as practical workshops with health professionals, using an individualized or standardized program, and so on. They can also differ widely in terms of content and content type: classes based on the transmission of information vs practice, training, and/or psychological interventions. The effectiveness of an education program has been shown to depend on all these features $(2,3,4)$.

Several education programs have been developed in different countries for rare endocrine diseases, notably for adrenal insufficiency. Indeed, the most recent French and international guidelines on the management of adrenal insufficiency highlight the importance of patient education, in particular for the administration of stressdose glucocorticoids and emergency hydrocortisone injections $(5,6,7)$. Most of these programs are based on learning and training and aim to allow patients to manage emergency situations by themselves and avoid potentially life-threatening adrenal crises $(1,8,9,10,11,12,13)$. Some programs include patients with secondary adrenal insufficiency as they also need to be educated on how to adapt hydrocortisone doses and perform hydrocortisone subcutaneous injections (14), and because morbidity and mortality are higher in patients both with primary and with secondary adrenal insufficiency $(1,12,15)$. An educational program has also recently been developed for patients with neuroendocrine tumors (NET) (16), based on individual and group learning and discussion sessions focusing on self-efficacy, showing significant improvement in patients' general self-efficacy, physical component scores of HRQoL and stress (16).

Patients with pituitary diseases could be included in programs such as these, but their specific hormonal imbalances - deficiencies or, in some conditions such as acromegaly or Cushing disease, hormone hypersecretion - and their corresponding needs and complaints must be taken into account. It is now well established that patients with pituitary diseases can have a poorer quality of life even when their disease is considered in remission $(17,18$, 19). It is, therefore, essential to provide these patients with individualized multidimensional education programs. Very few education programs have been developed for patients with pituitary diseases. To our knowledge, the only examples in the literature are a recently published program focusing on psychosocial issues in patients with the pituitary disease (20) and an educational nursing intervention program specifically designed for patients with Cushing syndrome (21). Detailed data on pituitaryoriented education programs are currently lacking. We have developed a new type of individualized education program for patients with pituitary diseases and in this study, we evaluated its efficacy in terms of quality of life outcomes, adaptability to patient needs, patient goal attainment and patient satisfaction.

\section{Subjects and methods}

\section{Patients}

Between 2012 and 2016, 171 patients were included in the pituitary education program and attended an 'educational diagnosis'. The first 53 patients who finished the education program in pituitary diseases held at the Conception hospital in Marseille, France, and completed the follow-up evaluation were included. All patients with pituitary diseases followed up in the department had the option of taking part in the 'pituitary disease education program' presented to them by their referring endocrinologist. Written informed consent was obtained from all patients who agreed to participate during the first meeting, before any involvement in group sessions. The ethics committee of Aix-Marseille University specifically approved this study.

\section{Program and data collection}

The therapeutic education program was developed by a team of health professionals (physicians, nurses, dieticians, psychologists) from the French Reference Centre for Rare Pituitary Diseases in the Department of Endocrinology of the Conception hospital, Marseille, France, in collaboration with five French support groups for patients with pituitary diseases (growth disorders, diabetes insipidus, adrenal diseases, McCune Albright syndrome, craniopharyngioma), listed in the 'Acknowledgements' section. The education program was approved by the regional health agency (Agence Régionale de Santé Provence-Alpes-Côte d'Azur) at the end of 2012 and was implemented at the beginning of 2013.

The main objective of this self-management education program is to improve the quality of life of patients with pituitary diseases. The program was designed to empower patients and increase self-efficacy in the treatment of 
their pituitary disease by improving their knowledge of management measures and treatments. It also aims to facilitate interactions with other patients suffering from related pathologies and to improve self-confidence and skills, especially in dealing with stressful and emergency situations.

Participating patients with pituitary diseases had an initial $\sim 1 \mathrm{~h}$ appointment with a health care provider for an 'educational diagnosis'. At the end of this meeting, patients set 'individualized education objectives' based on their knowledge and perceived strengths and weaknesses in dealing with their pituitary disease, and were asked to choose at least three out of eight possible sessions, designed to help them achieve these goals.

Eight different types of group sessions were organized regularly. These workshops involved three to eight patients, accompanied if they wished by one or two relatives and lasted about $2.5 \mathrm{~h}$. The instructors were either nurses, psychologists, medical doctors or dieticians, depending on the type of session. Members of the partnering patient support groups with knowledge of the disease and who had received training in education programs and methods also participated as 'expert patients' (Fig. 1).

Details of the eight sessions are reported in Supplementary data one (see section on supplementary materials given at the end of this article).

Once patients had completed the set of sessions they had selected, they had a 'final appointment'. The patient's progress in the program was reviewed with a focus on whether and to what extent the initial goals had been achieved. Additional abilities or objectives that they would have liked to achieve were also discussed. Further workshops (for reinforcement, consolidation) were proposed in some cases to achieve these new goals.

Follow-up evaluation questionnaires (SF36 and a follow-up evaluation questionnaire, Fig. 2) were sent to patients between 3 and 6 months after the final appointment.

\section{Statistical analysis}

Quantitative variables were expressed as mean \pm S.D. and were compared between groups using unpaired two-tailed Student's t-tests. Categorical variables were expressed as frequencies and compared using two-tailed Pearson's chi-square tests. Results were considered statistically significant at $P<0.05$.

\section{Results}

Among the 53 patients included in the study (33 women; mean age $53.5 \pm 17.0$ years), 14 had Cushing disease, 3 had acromegaly, 2 had suprasellar germinoma, 10 had isolated and 1 multiple pituitary deficiency, and 3 had isolated central diabetes insipidus. There were also cases of pituitary sarcoidosis $(n=1)$, pituitary apoplexy $(n=4)$, Sheehan syndrome $(n=3)$, non-secreting adenoma

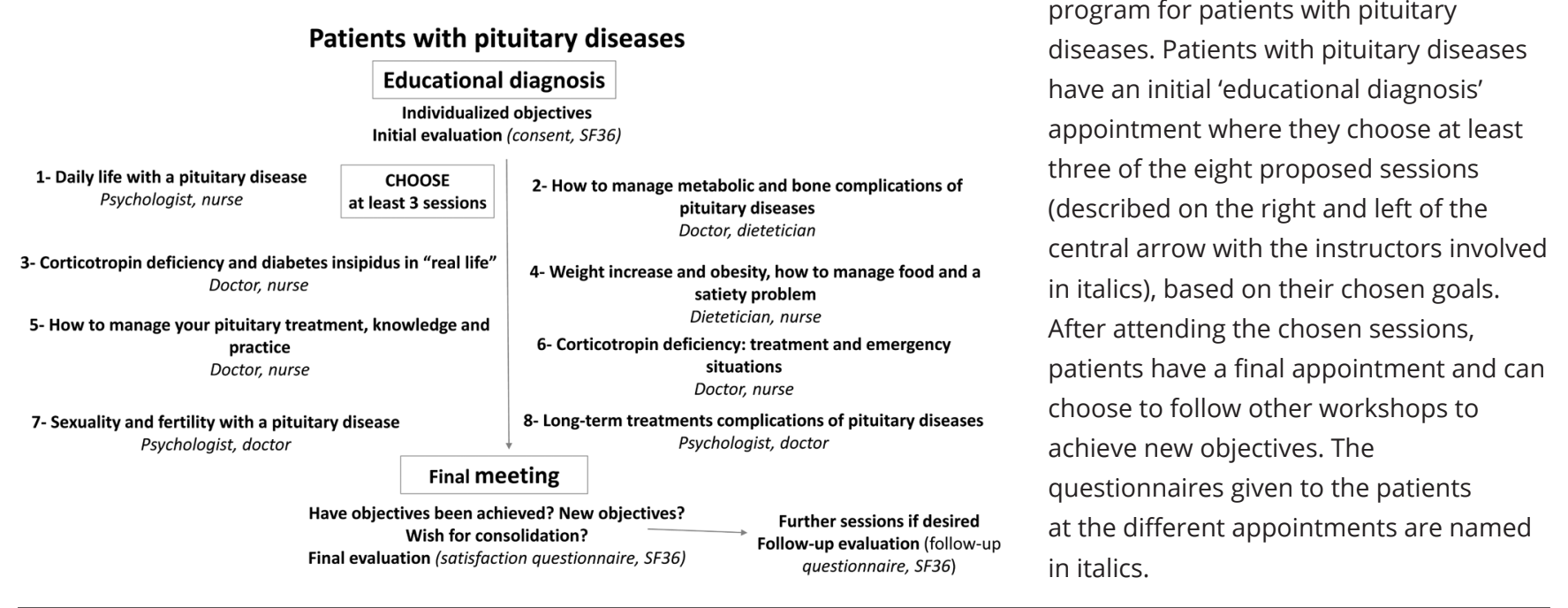

\section{Figure 1}

Design of an individualized education program in pituitary diseases. Flow diagram of the individualized education diseases. Patients with pituitary diseases have an initial 'educational diagnosis' appointment where they choose at least the eight proposed sessions described on the right and left of the central arrow with the instructors involved in italics), based on their chosen goals. After attending the chosen sessions, patients have a final appointment and can choose to follow other workshops to questionnaires given to the patients in italics. 


\section{Follow-up evaluation questionnaire}

Name: $\quad$ Date:
1- Having completed this program, would you say the management of your pituitary disease has been modified:

$\begin{array}{llll}\text { Radically A lot } & \text { A little } & \text { Very little } & \text { Not at all }\end{array}$

2- Having completed this program, would you say that your self-assurance in managing your pituitary disease has increased (regarding your knowledge, your treatment(s))

$\begin{array}{llll}\text { Radically A lot } & \text { A little Very little }\end{array}$

3- Can you list each of the treatments for your pituitary condition and their roles?

\begin{tabular}{|l|l|}
\hline Treatment & \multicolumn{1}{c|}{ Role } \\
\hline & \\
\hline & \\
\hline & \\
\hline & \\
\hline & \\
\hline
\end{tabular}

4- Describe your pituitary disease and its complications

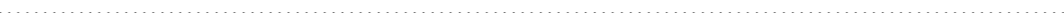

5- Have you had any problems related to your pituitary disease since completing the program that required hospitalization? If you have, please provide details.

(n)

Comments and suggestions:

$(n=5)$, craniopharyngioma $(n=4)$ or other parasellar lesions with pituitary deficiencies $(n=3$; one case each of meningioma, choristoma and glioma). The mean time between educational diagnosis and the final meeting was $11.0 \pm 7.6$ months.

\section{Questionnaires}

All 53 patients answered the satisfaction questionnaire, with a mean satisfaction level of $3.75 \pm 0.29$ (with a 1 (not satisfied) to 4 (very satisfied) scale). Patients were particularly satisfied by the attentiveness of the educational team (3.91/4) and the lowest average score (3.54/4) related to the tools and material used in the workshops. The patients also reported that the program met their expectations $(3.85 \pm 0.36)$, the contents of the workshops was useful $(3.83 \pm 0.38)$, the sessions improved their knowledge $(3.81 \pm 0.44)$, allowed them to share their experiences $(3.68 \pm 0.58)$ and will help them to manage their pituitary disease in daily life $(3.66 \pm 0.59)$.

\section{Figure 2}

Follow-up evaluation questionnaire.

Fifty-two patients filled in this

questionnaire, $5.5 \pm 3.0$ months

(mean \pm s.D.) after the final evaluation.

Fifty-two patients completed the follow-up evaluation questionnaire (32 women/20 men), $5.5 \pm 3.0$ months after the final meeting. The mean scores for the questions on changes to the management of their pituitary disease and on increased self-efficacy were $3.6 \pm 0.9$ and $3.8 \pm 0.7$ (out of 5), respectively. There were no reports of acute events requiring hospitalization in the period since completing the course. Patients 'comments highlighted the need for new sessions on pituitary disease-related professional issues and the possibility of additional educational tools.

Thirty-five patients (23 women, 12 men) completed the SF36 quality of life questionnaire before and after completing the program. The results at the start and end of the program (35 respondents) and at the follow-up evaluation (21 respondents) are listed in Table 1. Physical limitation scores were significantly higher at the end of the program than at the start $(P<0.001)$, and remained higher at the follow-up evaluation (initial vs follow-up, $P=0.05$ ). Patients also reported improved psychic limitation scores (initial vs final, $P=0.046$ ) that persisted at follow-up 
Table 1 Evolution in SF36 quality of life dimensions for patients attending the education program on pituitary diseases. Results are presented as mean \pm S.D. Higher scores indicate better quality of life.

\begin{tabular}{l}
\hline \\
\hline Physical functioning \\
Physical limitations \\
Physical pain \\
General health \\
perceptions \\
Energy/Vitality \\
Social functioning \\
Mental health \\
Psychic limitations \\
Physical component \\
summary \\
Mental component \\
summary
\end{tabular}

\begin{tabular}{ccc}
\cline { 1 - 1 } $\begin{array}{c}\text { Initial } \\
\text { evaluation score }\end{array}$ & & $\begin{array}{c}\text { Final } \\
\text { evaluation score }\end{array}$ \\
\cline { 1 - 1 } $76.1 \pm 15.1$ & & $75.9 \pm 15.4$ \\
$31.8 \pm 6.8$ & & $62.1 \pm 14.3$ \\
$75,0 \pm 13.7$ & & $75.2 \pm 12.3$ \\
$61.9 \pm 12.9$ & & $64.5 \pm 14.8$ \\
& & \\
$61.3 \pm 13.8$ & & $64.6 \pm 14.7$ \\
$73.1 \pm 17.5$ & & $75.7 \pm 18.8$ \\
$73.6 \pm 13.0$ & & $67.0 \pm 11.1$ \\
$70.5 \pm 21.8$ & & $76.6 \pm 21.1$ \\
$45.3 \pm 9.1$ & & $53.2 \pm 12.4$ \\
& & \\
$53.3 \pm 12.7$ & $52.5 \pm 13.9$ \\
&
\end{tabular}

\begin{tabular}{ccc}
$\begin{array}{c}\text { Follow-up } \\
\text { evaluation score }\end{array}$ & & $\boldsymbol{P}$ (initial vs final) \\
\cline { 1 - 1 } $74.6 \pm 11.1$ & & 0.94 \\
$42.7 \pm 18.5$ & & $<0.001$ \\
$73.4 \pm 13.9$ & & 0.92 \\
$62.7 \pm 14.9$ & & 0.16 \\
& & \\
$59.5 \pm 14.3$ & & 0.09 \\
$75.7 \pm 17.8$ & & 0.88 \\
$71.9 \pm 11.8$ & & $<0.001$ \\
$76.6 \pm 20.7$ & & 0.046 \\
$45.3 \pm 7.1$ & & 0.58 \\
$52.6 \pm 12.3$ & 0.95 \\
\end{tabular}

\begin{tabular}{|c|c|}
\hline $\boldsymbol{P}$ (final vs follow-up) & $\begin{array}{l}\boldsymbol{P} \text { (initial vs } \\
\text { follow-up) }\end{array}$ \\
\hline 0.40 & 0.62 \\
\hline$<0.001$ & 0.005 \\
\hline 0.39 & 0.06 \\
\hline 0.47 & 0.71 \\
\hline
\end{tabular}

(final vs follow-up, $P=1$ ). Mental health scores were significantly lower at the end of the program than on initial evaluation $(P<0.001)$, but increased significantly between the end of the program and the follow-up evaluation $(P=0.047)$.

\section{Patients' objectives}

We collected answers from 35 patients concerning their objectives at the start (educational diagnosis) and at the end (final appointment) of the program. The patients' objectives were classified in one of eight general categories and were considered totally, partially, or not achieved, and requiring strengthening or not (Fig. 3). The most widely chosen type of objective, by $29 / 35$ patients (82.9\%) was interacting and sharing experiences with other patients (first category). Learning how to manage emergency situations (sixth category) and improving their knowledge on their pituitary disease and its treatment and evolution (seventh category) were also priority objectives for more than half of the patients. Objectives classified as sharing experiences (first category) and improving self-confidence and autonomy in their condition (fifth category) were achieved by more than three quarters of patients and those for managing emergency situations (sixth category) were achieved by two thirds of patients. At the final meeting, $18 / 35$ patients $(51.4 \%)$ chose new objectives to achieve or reinforce. The objectives most commonly chosen for this consolidation phase concerned the patients' knowledge of their condition and treatments (seventh category, six patients), how to manage and adapt treatments (fourth category, four patients) and dietary management (eighth category, four patients).

\section{Discussion}

This education program was designed to develop the selfmanagement skills of patients with a pituitary disease. To our knowledge, this is the first program for patients with

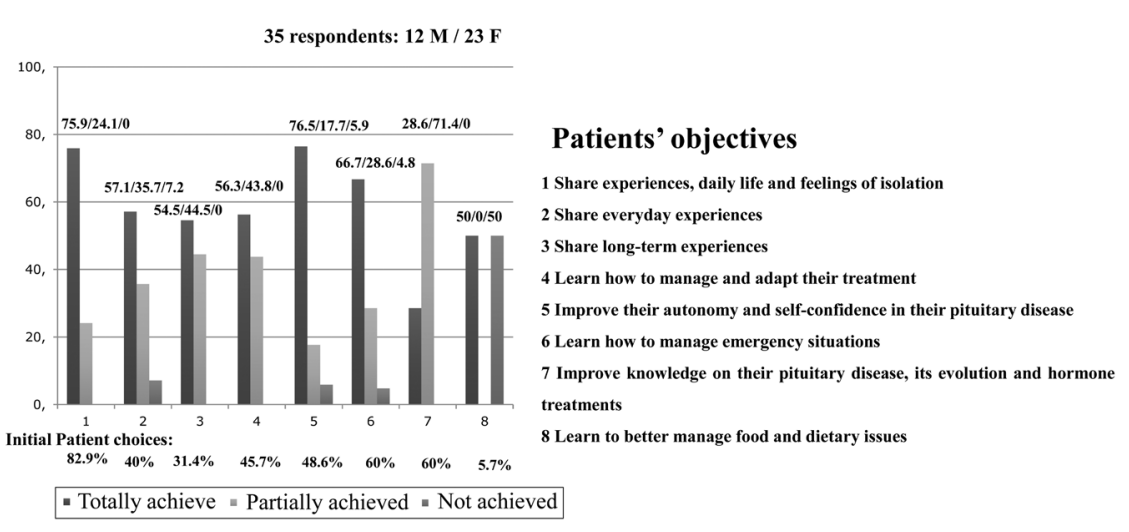

\section{Figure 3}

Patients' objectives. The proportions of patients who reported completely, partially and not reaching their objectives are shown in black, light grey and grey, respectively, for each objective (numbered 1-8) with the corresponding percentages shown above each group of bars. The proportions of patients who initially chose each objective are shown below the plot (objectives listed on the right side from 1 to 8 ). 
endocrine diseases whose content can be customized to such an extent, focusing on patients' individual needs and objectives, and covering a wide variety of subjects, from the knowledge of pituitary diseases, hormones and healthcare, to psychosocial and practical aspects of everyday life.

Two other education programs for patients with pituitary diseases have been published in the last few years. Andela et al. recently implemented a self-management program in pituitary diseases targeting psychosocial issues and including patients' partners. They report promising results from a randomized controlled trial involving 174 patients in two groups, with improved self-efficacy persisting up to 6 months after the end of the program (20). Patients attended 8 weekly sessions of 90 min in groups of five to seven participants stratified by disease. At the end of the program, patients stated that they would have liked to receive more medical information about their disease (20). Since patients with the pituitary disease have diseasespecific needs $(22,23)$ and are known to have an impaired quality of life that can be improved but not normalized by surgical and pharmacological interventions (24), we also chose to include workshops on psychosocial issues in our program (sessions 1, 7 and 8, led by a psychologist), in addition to the informal exchanges that took place during each group learning session. The second recently published educational program, developed for patients with Cushing's syndrome, was based on five visits over 9 months (including four $2 \mathrm{~h}$ educational sessions), and focused on the disease and its comorbidities, treatment and management, with no workshop devoted to its psychosocial aspects (21). In a randomized controlled study of 61 patients, those in the intervention group had improved physical activity, a more healthy lifestyle, better sleep patterns and lower pain than those in the control group at the end of the program, leading to better health-related quality of life and reduced health resources consumption (21). Our patients reported a decrease in physical role limitations at the end of the program that persisted until the follow-up evaluation. Psychic limitations were also significantly reduced at the end of the program, while the mental health score worsened and then returned to the baseline level, maybe because patients had to get used to the change in management of their pituitary disease.

We did not observe significant changes in terms of physical functioning or pain, general health perceptions, energy/vitality or social functioning. This may be because patients enrolled had a variety of pituitary pathologies and were reassessed several months after the end of the program, while in Martinez-Momblan et al. study, the patients all had Cushing's syndrome and were evaluated at the end of the study only, with no follow-up questionnaire (21). Indeed, Andela et al. found that the reported reduction in bother from mood problems at the end of the program had disappeared at 6 months' follow-up evaluation (20). Furthermore, since only 35 of the 53 patients in our study completed the SF36 questionnaire both at the beginning and at the end of the program and only 21 at follow-up may explain why some of the differences did not reach the significance threshold due to a lack of statistical power. Finally, mirroring the reduction in health resources consumption observed by Martinez-Momblan et al., no patient in our study reported any acute event requiring hospitalization in the few months between the end of the program and the follow-up evaluation.

The personalization and adaptability of the program to individual needs and requirements is also an important factor in promoting patient involvement and adherence, which are essential for learning and for changing behaviors. The time requirements of such programs can lead to low participation and high rates of attrition, so adapting contents to the specific needs and pathologies of participants is crucial to generate and maintain interest (25). In our program, patients initially choose at least three sessions to achieve their individual goals with a wide variety of combinations of sessions. We hypothesized that making this education program customizable would limit the attrition rate, which can be as high as 50\% for some programs (25). While we were unable to test this hypothesis because the education sessions were scheduled on demand and there was no time limit for participants to complete their chosen set, patient satisfaction rates, especially regarding their expectations, the content of the sessions and learning outcomes, indicate that the design of the program and its adaptability to their needs was well received by patients and met their expectations.

In a recent study by Burger-Stritt et al. (9), 95\% of the patients with adrenal insufficiency participated in an education program where they received general information on the disease and practical training on selfinjection and how to adjust daily doses of hydrocortisone. Despite this education program, glucocorticoid injections were only performed by patients or their relatives in 26 of the 59 emergency situations, and at least $15 \%$ of patients failed to adjust their oral glucocorticoid dose. The main reasons reported for not performing self-injection were an impaired health condition and a too high inhibition threshold. The authors recommend that patients should be educated repeatedly on dose adjustment and 
hydrocortisone self-injection (9). Andela et al. (20) also emphasize the importance of additional refreshing sessions in the first year after completing the program or later, and on adjusting the sessions to patients' needs for consolidation, which is necessary for the self-management of chronic diseases in general (25). One of the strengths of our program is the final appointment in which patients reassess their situation in light of their newly acquired knowledge and skills and consider any new needs related to their pituitary disease. Indeed, more than half of our patients chose to set new objectives or to strengthen skills.

The biases and limitations of this study are typical of any retrospective study based on self-reported questionnaire assessments. Further limitations are the small study size, due to the rarity of the pituitary diseases involved, and the length of the program, which lasted 11 months on average and varied between patients. As education is an integrative process, the patient's family and social environment - and the possible changes in these during the program - should also be taken into account to fully understand the results of the program. The low incidence of pituitary diseases meant that we chose not to divide the study population into separate disease-specific groups (acromegaly, Cushing disease and so on), but on the contrary, to make the program inclusive of all pituitary disease subtypes. Patients mostly commented positively on this diversity, reporting that they found it enriched their exchanges.

The originality and richness of this pituitary education program lies in the ability of patients to personalize the set of sessions they attend and to make contents evolve with the evolution of their needs. The program is set to evolve in the future with the inclusion of new topics and learning tools, new types of health professionals, based on recurring remarks. A new workshop on the professional issues caused by pituitary diseases is thus being developed in collaboration with a social worker, as pituitary diseases are known to affect social functioning and health-related absenteeism $(26,27)$. We would like to involve more partners, in general, to offer the best possible support to pituitary disease patients, particularly in terms of their psychosocial well-being (28). We are developing new e-learning tools to complement the already available educational videos on hydrocortisone injections. This will include videoconference sessions allowing disabled or mobility-impaired patients to take part in virtual workshops and education sessions and the development of a smartphone application-specific for pituitary disorders providing with customized information and allowing follow-up of some clinical, treatment-related or biological parameters. These new tools will aim at optimizing selfmanagement, autonomy, compliance and distant follow-up of pituitary patients. Lastly, we are developing a specific questionnaire on the management of hydrocortisone and desmopressin treatments to more objectively evaluate how these changes in our patients after completing the course.

This first evaluation of our individualized selfmanagement education program for patients with pituitary diseases revealed promising results in terms of patient satisfaction, quality of life, skills progression, self-confidence, knowledge of their pituitary disease, its treatment and management. A wider roll-out is now required to evaluate its effect on a larger number of patients.

To conclude, this study supports our view that alongside surgical and pharmacological treatments, education programs such as the one considered here are essential for the well-being of patients with pituitary diseases. The development and dissemination of such programs will have a positive impact on public health, as educated patients manage their symptoms more effectively, and thereby also potentially reduce overall healthcare costs $(21,29,30)$.

\section{Supplementary materials}

This is linked to the online version of the paper at https://doi.org/10.1530/ EJE-20-0652.

\section{Declaration of interest}

The authors declare that there is no conflict of interest that could be perceived as prejudicing the impartiality of this study.

\section{Funding}

This research did not receive any specific grant from any funding agency in the public, commercial or not-for-profit sector.

\footnotetext{
Acknowledgements

The authors thank all the patients who took part in the education program, in particular those who collaborated as expert patients. They are grateful for the input and support received from the following patients' associations, especially in the development of the program and for their active participation in the workshops: 'GRANDIR' (the French association for patients with growth disorders); 'AFDI' (the French association for patients with diabetes insipidus); 'Association surrénales' (the French adrenal association); 'ASSYMCAL' (the French McCune Albright syndrome association) and 'craniopharyngiome-solidarité' (the French association for patients with craniopharyngioma). The authors also thank the members of the AP-HM's healthcare quality department for their help in designing this program and the endocrinologists who have referred their patients to the pituitary education program.
} 


\section{References}

1 Hahner S, Spinnler C, Fassnacht M, Burger-Stritt S, Lang K, Milovanovic D, Beuschlein F, Willenberg HS, Quinkler M \& Allolio B. High incidence of adrenal crisis in educated patients with chronic adrenal insufficiency: a prospective study. Journal of Clinical Endocrinology and Metabolism 2015100 407-416. (https://doi. org/10.1210/jc.2014-3191)

2 Lagger G, Pataky Z \& Golay A. Efficacy of therapeutic patient education in chronic diseases and obesity. Patient Education and Counseling 201079 283-286. (https://doi.org/10.1016/j. pec.2010.03.015)

3 Osborn RL, Demoncada AC \& Feuerstein M. Psychosocial interventions for depression, anxiety, and quality of life in cancer survivors: meta-analyses. International Journal of Psychiatry in Medicine 200636 13-34. (https://doi.org/10.2190/EUFN-RV1K-Y3TRFKOL)

4 Warsi A, Wang PS, LaValley MP, Avorn J \& Solomon DH. Selfmanagement education programs in chronic disease: a systematic review and methodological critique of the literature. Archives of Internal Medicine 2004164 1641-1649. (https://doi.org/10.1001/ archinte.164.15.1641)

5 Bornstein SR, Allolio B, Arlt W, Barthel A, Don-Wauchope A, Hammer GD, Husebye ES, Merke DP, Murad MH, Stratakis CA et al. Diagnosis and treatment of primary adrenal insufficiency: an Endocrine Society clinical practice guideline. Journal of Clinical Endocrinology and Metabolism 2016101 364-389. (https://doi. org/10.1210/jc.2015-1710)

6 Husebye ES, Allolio B, Arlt W, Badenhoop K, Bensing S, Betterle C, Falorni A, Gan EH, Hulting AL, Kasperlik-Zaluska A et al. Consensus statement on the diagnosis, treatment and follow-up of patients with primary adrenal insufficiency. Journal of Internal Medicine 2014275 104-115. (https://doi.org/10.1111/joim.12162)

7 Guignat L. Therapeutic patient education in adrenal insufficiency. Annales D'endocrinologie 201879 167-173. (https://doi.org/10.1016/j. ando.2018.03.002)

8 Burman P, Mattsson AF, Johannsson G, Höybye C, Holmer H, Dahlqvist P, Berinder K, Engström BE, Ekman B, Erfurth EM et al. Deaths among adult patients with hypopituitarism: hypocortisolism during acute stress, and de novo malignant brain tumors contribute to an increased mortality. Journal of Clinical Endocrinology and Metabolism 201398 1466-1475. (https://doi.org/10.1210/jc.20124059)

9 Burger-Stritt S, Kardonski P, Pulzer A, Meyer G, Quinkler M \& Hahner S. Management of adrenal emergencies in educated patients with adrenal insufficiency - a prospective study. Clinical Endocrinology 201889 22-29. (https://doi.org/10.1111/cen.13608)

10 Schad R, Schneider PJ \& Nold EG. Reimbursable pharmacy teaching program for adrenalectomy patients. American Journal of Hospital Pharmacy 197936 1212-1214. (https://doi.org/10.1093/ ajhp/36.9.1212)

11 Guignat L. Therapeutic education in adrenal insufficiency: a tool insufficiently used to prevent or treat early acute adrenal insufficiency. Presse Medicale 201443 444-452. (https://doi. org/10.1016/j.lpm.2014.01.008)

12 Repping-Wuts HJWJ, Stikkelbroeck NMML, Noordzij A, Kerstens M $\&$ Hermus ARMM. A glucocorticoid education group meeting: an effective strategy for improving self-management to prevent adrenal crisis. European Journal of Endocrinology 2013169 17-22. (https://doi. org/10.1530/EJE-12-1094)

13 Vidmar AP, Weber JF, Monzavi R, Koppin CM \& Kim MS. Improved medical-alert ID ownership and utilization in youth with congenital adrenal hyperplasia following a parent educational intervention. Journal of Pediatric Endocrinology and Metabolism 201831 213-219. (https://doi.org/10.1515/jpem-2017-0435)
14 Hahner S, Burger-Stritt S \& Allolio B. Subcutaneous hydrocortisone administration for emergency use in adrenal insufficiency. European Journal of Endocrinology 2013169 147-154. (https://doi.org/10.1530/ EJE-12-1057)

15 Bancos I, Hahner S, Tomlinson J \& Arlt W. Diagnosis and management of adrenal insufficiency. Lancet: Diabetes and Endocrinology 20153 216-226. (https://doi.org/10.1016/S22138587(14)70142-1)

16 Haugland T, Veenstra M, Vatn MH \& Wahl AK. Improvement in stress, general self-efficacy, and health related quality of life following patient education for patients with neuroendocrine tumors: a pilot study. Nursing Research and Practice 20132013 695820. (https://doi. org/10.1155/2013/695820)

17 De Bucy C, Guignat L, Niati T, Bertherat J \& Coste J. Health-related quality of life of patients with hypothalamic-pituitary-adrenal axis dysregulations: a cohort study. European Journal of Endocrinology 2017 177 1-8. (https://doi.org/10.1530/EJE-17-0048)

18 Kyriakakis N, Lynch J, Gilbey SG, Webb SM \& Murray RD. Impaired quality of life in patients with treated acromegaly despite long-term biochemically stable disease: results from a 5-years prospective study. Clinical Endocrinology 201786 806-815. (https://doi.org/10.1111/ cen.13331)

19 van der Klaauw AA, Kars M, Biermasz NR, Roelfsema F, Dekkers OM, Corssmit EP, van Aken MO, Havekes B, Pereira AM, Pijl H et al. Disease-specific impairments in quality of life during long-term follow-up of patients with different pituitary adenomas. Clinical Endocrinology 200869 775-784. (https://doi.org/10.1111/j.13652265.2008.03288.x)

20 Andela CD, Repping-Wuts H, Stikkelbroeck NMML, Pronk MC, Tiemensma J, Hermus AR, Kaptein AA, Pereira AM, Kamminga NGA $\&$ Biermasz NR. Enhanced self-efficacy after a self-management programme in pituitary disease: a randomized controlled trial. European Journal of Endocrinology 2017177 59-72. (https://doi. org/10.1530/EJE-16-1015)

21 Martínez-Momblán MA, Gómez C, Santos A, Porta N, Esteve J, Úbeda I, Halperin I, Campillo B, Guillaumet M, Webb SM et al. A specific nursing educational program in patients with Cushing's syndrome. Endocrine 201653 199-209. (https://doi.org/10.1007/ s12020-015-0737-0)

22 Andela CD, Niemeijer ND, Scharloo M, Tiemensma J, Kanagasabapathy S, Pereira AM, Kamminga NGA, Kaptein AA \& Biermasz NR. Towards a better quality of life (QoL) for patients with pituitary diseases: results from a focus group study exploring QoL. Pituitary 201518 86-100. (https://doi.org/10.1007/s11102-0140561-1)

23 Andela CD, Lobatto DJ, Pereira AM, van Furth WR \& Biermasz NR. How non-functioning pituitary adenomas can affect healthrelated quality of life: a conceptual model and literature review. Pituitary 201821 208-216. (https://doi.org/10.1007/s11102-0170860-4)

24 Andela CD, Scharloo M, Pereira AM, Kaptein AA \& Biermasz NR. Quality of life (QoL) impairments in patients with a pituitary adenoma: a systematic review of QoL studies. Pituitary 201518 752-776. (https://doi.org/10.1007/s11102-015-0636-7)

25 Newman S, Steed L \& Mulligan K. Self-management interventions for chronic illness. Lancet 2004364 1523-1537. (https://doi. org/10.1016/S0140-6736(04)17277-2)

26 Lobatto DJ, Steffens ANV, Zamanipoor Najafabadi AH, Andela CD, Pereira AM, van den Hout WB, Peul WC, Vliet Vlieland TPM, Biermasz NR \& van Furth WR. Work disability and its determinants in patients with pituitary tumor-related disease. Pituitary 201821 593-604. (https://doi.org/10.1007/s11102-018-0913-3)

27 Hahner S, Loeffler M, Fassnacht M, Weismann D, Koschker AC, Quinkler M, Decker O, Arlt W \& Allolio B. Impaired subjective health status in 256 patients with adrenal insufficiency on standard therapy 
based on cross-sectional analysis. Journal of Clinical Endocrinology and Metabolism 200792 3912-3922. (https://doi.org/10.1210/jc.20070685)

28 Andela CD, Tiemensma J, Kaptein AA, Scharloo M, Pereira AM, Kamminga NG \& Biermasz NR. The partner's perspective of the impact of pituitary disease: looking beyond the patient. Journal of Health Psychology 201924 1687-1697. (https://doi. org/10.1177/1359105317695427)
29 Dibley L, Norton C \& Jones R. Informing a patient education programme for GORD: a literature review. Gastrointestinal Nursing 20097 28-37. (https://doi.org/10.12968/gasn.2009.7.5.42907)

30 Lobatto DJ, van den Hout WB, Zamanipoor Najafabadi AH, Steffens ANV, Andela CD, Pereira AM, Peul WC, van Furth WR, Biermasz NR \& Vliet Vlieland TPM. Healthcare utilization and costs among patients with non-functioning pituitary adenomas. Endocrine 201964 330-340. (https://doi.org/10.1007/s12020-019-01847-7)

Received 12 June 2020

Revised version received 03 August 2020

Accepted 11 September 2020 